\title{
Metamorphosis of a Child Immunity
}

\author{
George Tsibu' ${ }^{*}$, Debbi Werdeiman ${ }^{2}$ and Clement Baffoe Yeboah ${ }^{2}$ \\ ${ }^{1}$ Agona Nyakrom.C/R. Ghana \\ ${ }^{2}$ Department of Chemistry and Physics, Environmental Scientist, Pennsylvania, USA \\ *Corresponding Author: George Tsibu, Agona Nyakrom. C/R. Ghana.
}

Received: November 01, 2019; Published: November 13, 2019

DOI: 10.31080/ASPE.2019.02.0183

Study's piloted shows that if your child like fighting physical live him, Don't molest him or her but allow the child to function in in his or her activities to build up his or her immunity which comprises the child Albumin compactivity, sympathetic and parasympathetic nerves and Blood compatibility and Blood incompatibility flowing from the Power house of the heart and the nerves. Albumin, Blood tissues and its synthetic: The sympathetic nervous system is also known as the fight or flight mode: It increases your heart rate Like you're about to fight. The parasympathetic nervous system does the opposite of the sympathetic system, It reduces your heart rate. It controls normal stuffs like defecation and others: The adrenalin and noradrenalin aspect is by the Sympathetic. Adrenalin and noradrenalin increases heart rate during a fight. All these are done by the sympathy: By causing the release of these hormones adrenalin and noradrenalin from the adrenal medulla Which therefore increases heart rate. As for a child. It is almost always related to dietary deficiencies. Rarely, it can relate to enzymatic problems that are more congenital but that would be unusual and would only be known with testing. Low albumin usually related to low protein. This usually relates are almost always relates to malnutrition. As for a child. It is almost always related to dietary deficiencies. Rarely, it can relate to enzymatic problems that are more congenital but that would be unusual and would only be known with testing. Pediatric Lee, you will be affecting bone growth bone strength growth pattern cognitive functioning. Sufficient proteins and proper nutrients, proper diet are vital in both of these situations. Kwashiorkor Is the technical or medical term for protein-based malnutrition. Marasmus is a term for generalized mail nutrition or less than needed caloric intake The $\mathrm{Rh}$ factor (i.e., Rhesus factor) is a red blood cell surface antigen that was named after the monkeys in which it was first discovered. Rh incompatibility, also known as $\mathrm{Rh}$ disease, is a condition that occurs when a woman with Rhnegative blood type is exposed to Rh-positive because doctors are aware of the danger of using the. There are many precautions in place to reduce the chances of a mistake. Your nurse know to look for certain symptoms during and after your transfusion that might mean you're having a reaction. This allows them to provide you with treatment as quickly, ABO Incompatibility Reaction. Human error is the most likely cause of an $\mathrm{ABO}$ incompatibility reaction. If your transfusion uses the wrong blood type, it could be the result of mislabeled blood, incorrectly completed forms, or a failure to check donated blood before the transfusion. If you have an $\mathrm{ABO}$ incompatibility reaction, you'll have symptoms within a few minutes of receiving a transfusion. These may include: a strong feeling that something bad is about to happen fever and chills. breathing difficulties, muscle aches, nausea, chest, abdominal, or back pain, blood in your urine, jaundice. Humans were not the largest, fastest, or fiercest animal. Early humans survived by their wits and their ability to collaborate. What does this have to do with being afraid to speak in public? Whether you want to increase your confidence in every area of your life or want to make an extra income.

\section{Volume 2 Issue 12 December 2019 \\ (C) All rights are reserved by George Tsibu., et al.}

